\title{
Intensity of Arakawa's Reaction and Blood Platelet Count; Change of Platelet Count on B=Vitamin Administration.
}

60th* Report of the Peroxidase Reaction.

\author{
By \\ Jun Kimura. \\ (木 村 順) \\ (From the Department of Pediatrics, Faculty of Medi- \\ cine, Tohoku Imperial University, Sendai. \\ Director: Prof. A. Sato.)
}

In the 47th Report on the Peroxidase Reaction I have stated on the basis of blood platelet count most of the healthy mothers secreting human milk negative to A rakawa's reaction** were in a state of avitaminosis $B$, and that negative A rakawa's reaction could be an early sign of avitaminosis B in an apparently healthy lactant. This conclusion was deduced from strongly Arakawa-positive and completely A rakaw a-negative cases alone: So in the 59th Report ${ }^{9}$ on the Peroxidase Reaction, I investigated cases of mothers with milk of Arakawa's reaction of intermediate strengths, and came to the conclusion that these mothers or intermediate cases were either in a state of $\mathrm{B}$-avitaminosis or on the brink of B-avitaminosis. In the present paper I desire to report further on the result of the investigation with a larger number of cases, especially of intermediate casesmothers with milk of Arakawa's reaction of intermediate strengths.

* This is my $3 \mathrm{r}$ d report on the relation between avitaminosis $B$ and blood platelet count.

** A rakawa-positive case=strongly or normally A rakawa-positive case

= clinically Arak awa-positive case

$=$ mother with milk with strong or normal

Arakawa's reaction

$=$ mother with A.R. $(t+) 1^{\prime}$ or $(H t) 1^{\prime}$

Mother A.R. $(+) 1^{\prime}$ or A.R. $(+t) 2^{\prime}$ for instance, is chemically an A r a k a w a-positive case, but clinically an A rak a wa-negative case.

1) J. Kimura, Tohoku J. Exp. Med., 1934, 23, 494.

2) J. Kimura, Tohoku J. Exp. Med., 1935, 27, 360. 
Furthermore, I desire to relate the result of the blood platelet count, or rather the change of the count on an administration of vitamin $B$ in some intermediate cases, which in practical medicine are to be con-

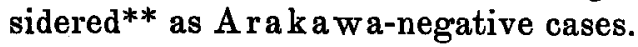

\section{Method of Experiment.}

1. Materials. As stated above, mothers with human milk of A rakawa's reaction of different intensities were examined, though strongly Arakawa-positive and completely Arakawa-negative cases were also examined.

All the lactants were "healthy," and of course they had not been taking vitamin B preparations. It should be noted that I excluded mothers who had menses at the time. ${ }^{3)}$

2. Platelet count. I used Lampert's method. The ear lobe was cleaned with ether, and a cut was made with Frank's needle. Blood was taken in the "A-thrombit" and diluted with Tyrode's solution. After shaking the pipette for a few minutes, the sixth drop of the contents was examined for blood platelets. Blood taking took place between 10 and 11 A.M., when mothers were in a fasting state.

\section{Result of Experiment.}

In the present work I investigated 125 cases, of which the most were lactants with milk of Arakawa's reaction of intermediate strength. As to strongly Arakawa-positive and completely Arak a wa-negative cases, there were only a few of them, mainly of the former. Therefore, I made statistics of the cases including those reported in the $47 \mathrm{th}^{12}$ and 59th ${ }^{2)}$ Report of the Peroxidase Reaction as well as of the cases alone reported in the present paper.

1. Blood platelet count in strong Arakawa-positive cases.

There were only 4 Arak a wa-positive cases, or cases of mothers with milk strongly positive to Arakawa's reaction. But all these cases showed a blood platelet count under 300000 per $\mathrm{cmm}$. two of them under 200000 (Cf. Table I and Table IV).

2. Blood platelet count in completely A rak a wa-negative cases. There were 12 cases of mothers with completely or almost com-

3) T. Ootsuka, Kyotofuritsu Ikadaigaku Zasshi., 1932, 6, 2434.

4) H. L a mpert. Verh. Dtsch. Ges. inn. Med., 1931, 43, 92. 

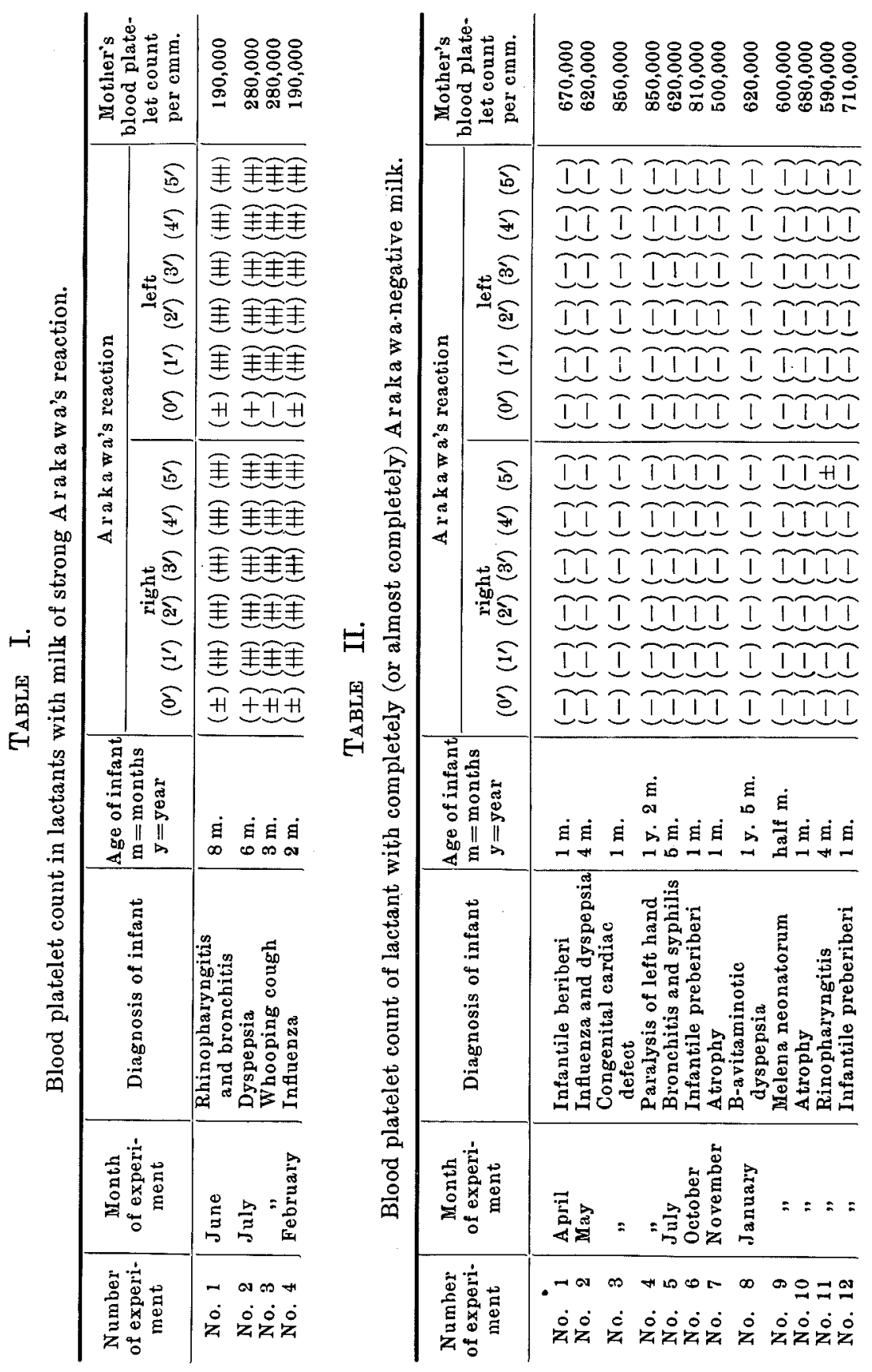
pletely negative A r a k a wa's reaction. 3 cases of these showed a count over 800000 per $\mathrm{cmm}$, and the case with the smallest count was 500 000 . It will be seen that in regard to the blood platelet count there is a very wide margin between A raka w a-positive and-negative cases (Cf. Table II and Table IV).

3. Blood platelet count in cases with Arakawa's reaction of intermediate strengths.

There are as many as 109 cases with intermediate Arakawa's reaction. Of these not a single case showed a platelet count under 200000 , and in only $8.3 \%$ of all the cases the count was between 200 000 and 300000 . If the normal fluctuation is between 100000 and 400000 , then only $45.9 \%$ of all the 101 cases came within this range, while the majority of them-54.1\%-were beyond that range. But not a single case showed a higher count that 700000 . And there was only $6.4 \%$ of all the cases which came between 600000 and 700000 . A glance at TableIV(A) and TableIV(B) will show very clearly the relation between A ra k a wa-positive, -negative and intermediate cases.

The relation given in Table IV will present itself in another form, if the average of the platelet counts in each group of cases is shown (Cf. Table V).

4. Blood platelet count in 325 cases.

In this paragraph the result of all the 325 cases including all the cases reported in the $47 \mathrm{th}^{12}$ and the $59 \mathrm{th}^{2}$ Reports on the Peroxidase Reaction will be stated. As is shown in Table VI (A), of 65 Arakawa-positive cases, the majority $(59.7 \%)$ came under the column $200000-300000$; of 153 intermediate cases the largest percentage (35.9\%) under the column $300000-400000$; and of 105 Arakawanegative cases the largest percentage (34.3\%) came under the column $500000-600000$. A more precise distribution will be seen from the Table (Cf. Table VI A).

A simpler distribution than was shown in Table VI (A) will be shown in Table VI (B), from which one can conclude that almost all the cases of A rakawa-positive cases are of the blood platelet count of $100000-400000$, that almost half the number of intermediate cases are of $200000-400000$ and the other half are of the count $400000-$ 700000 , and that the majority of A ra kawa-negative cases are of the count $400000-700000$. Further, one can see that there is not a single instance among A rakaw a-positive or intermediate cases that is of the count $700000-1000000$, but more than $20 \%$ of Arakawanegative cases are of the count $700000-1000000$. 


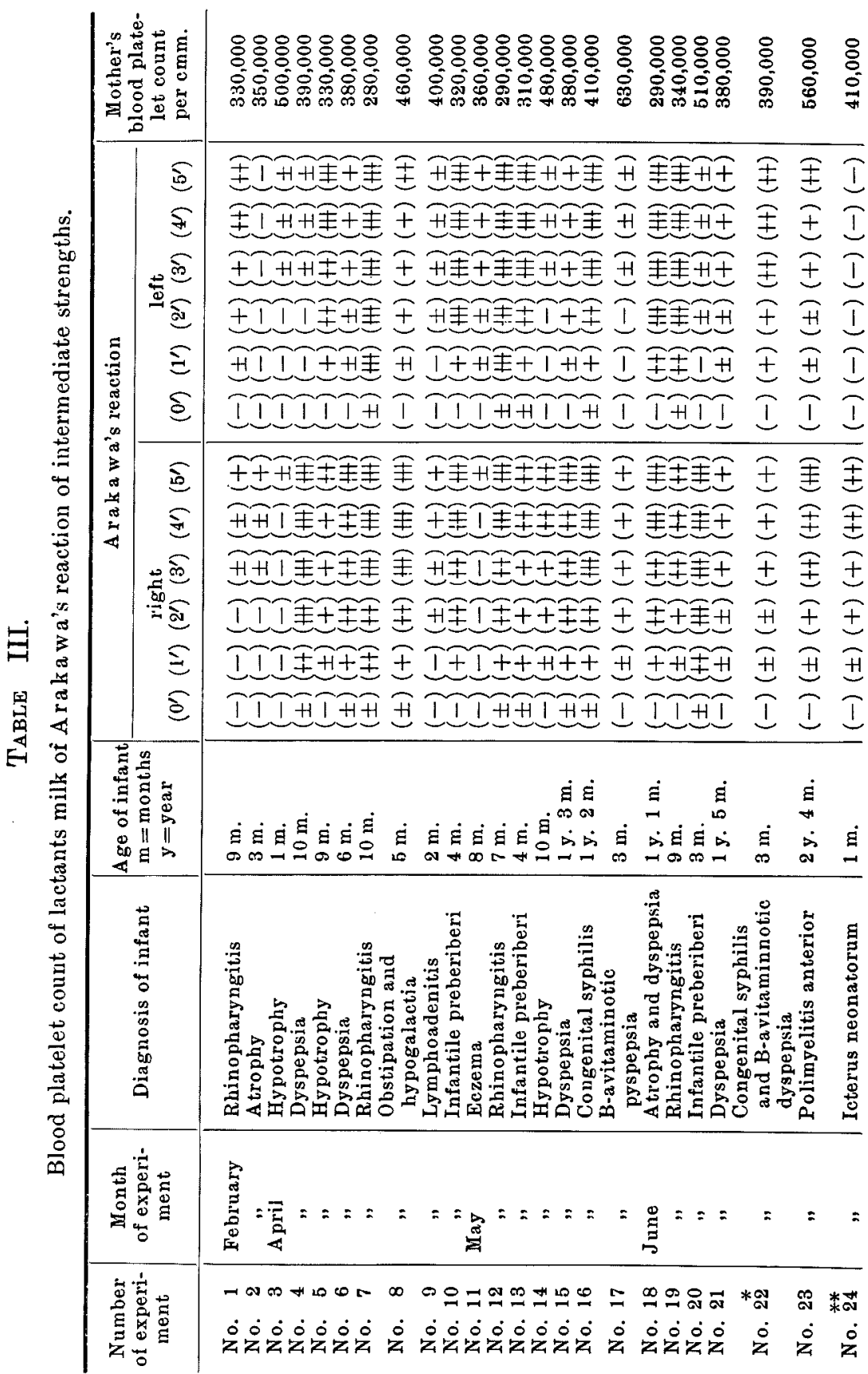




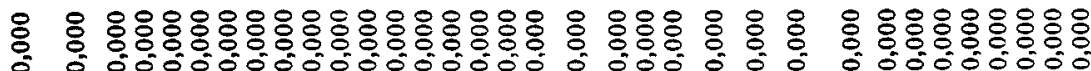

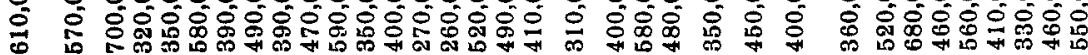

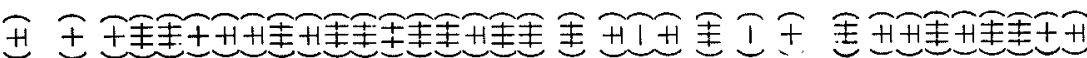

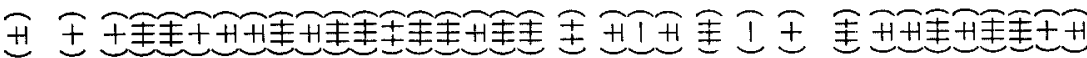

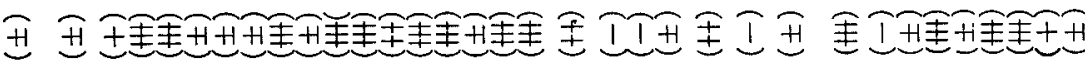

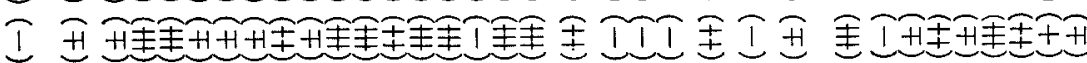

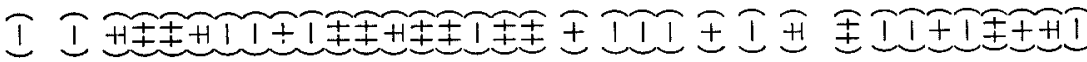

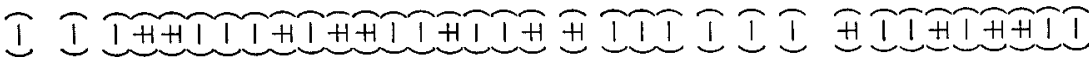

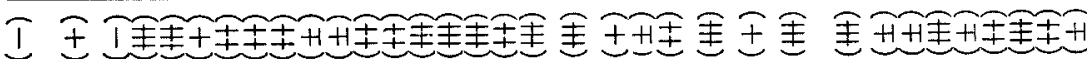

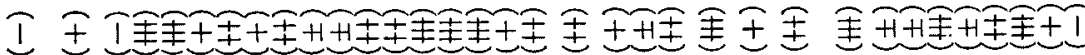

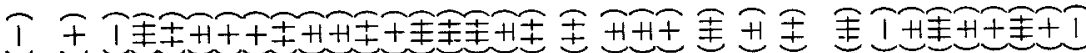

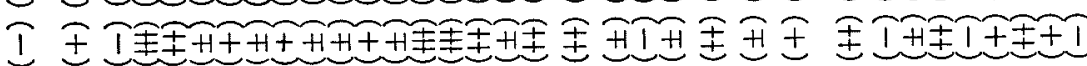

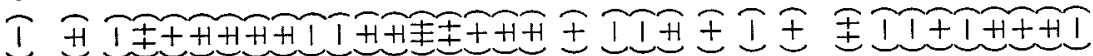

IIIHAIIIIIITHETI HIIIII HIIHIIHII

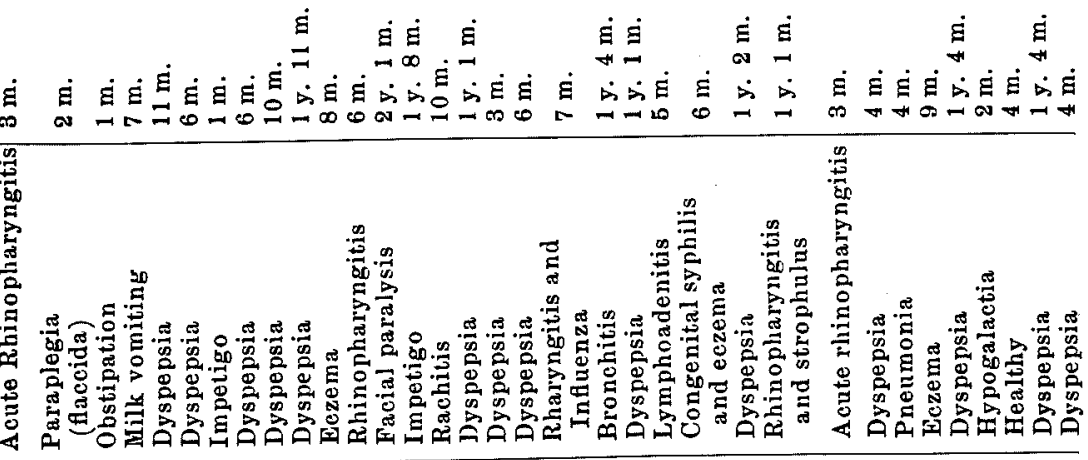

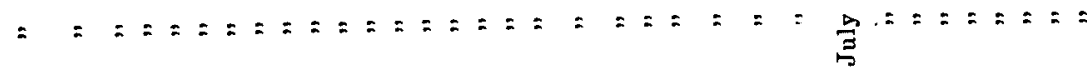

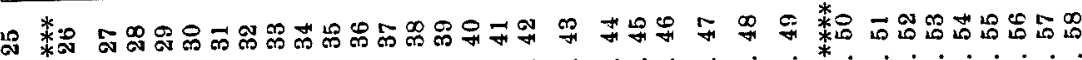

$\because \quad \dot{0} \dot{0} \dot{0} \dot{0} \dot{0} \dot{0} \dot{0} \dot{0} \dot{0} \dot{0} \dot{0} \dot{0} \dot{0} \dot{0} \dot{0} \dot{0} \dot{0} \dot{0} \dot{0} \dot{0} \dot{0} \dot{0}$

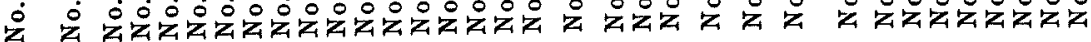




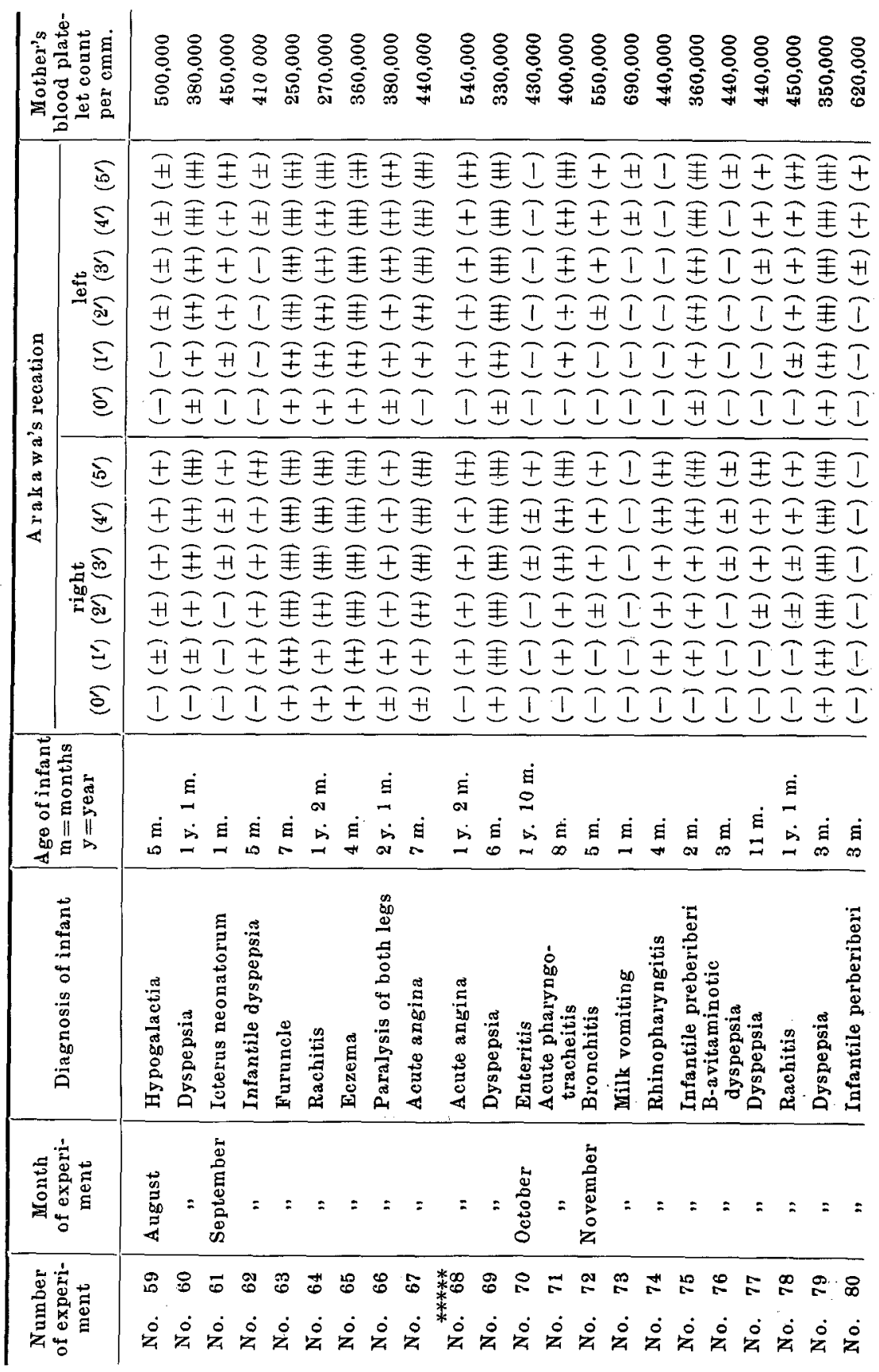




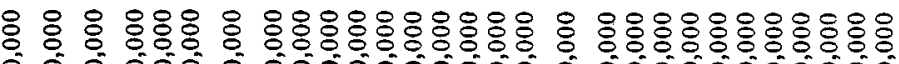

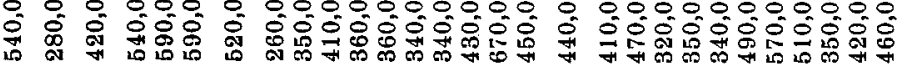

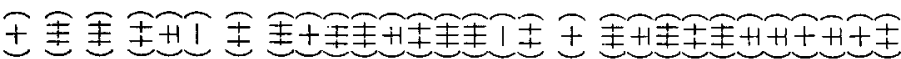

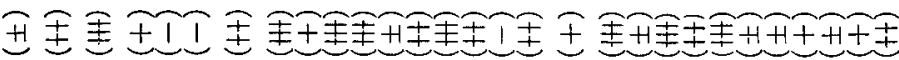

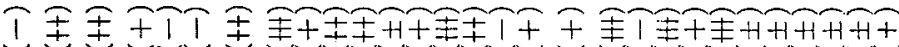

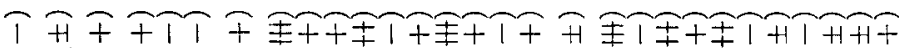

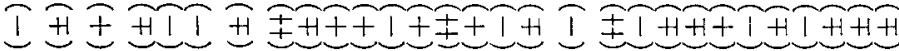
IIIIIITIIIIIIHIIII FIIIIIIIHII

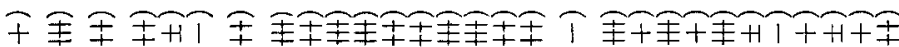

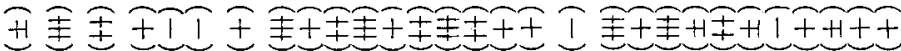

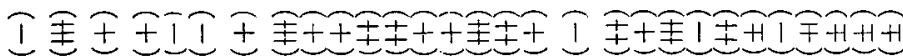

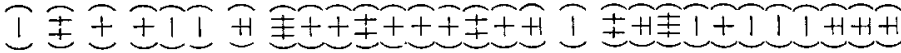

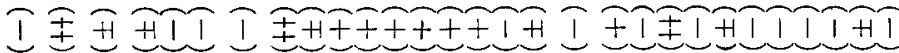
I

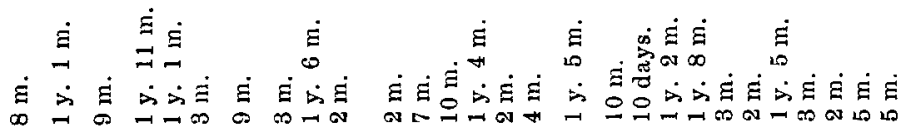

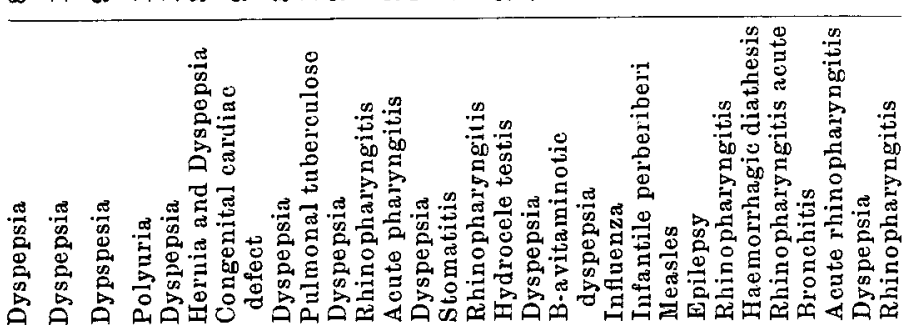

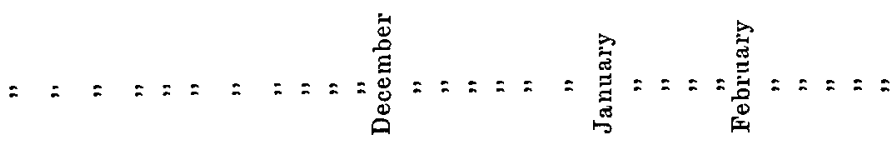

ద $\dot{0} \dot{0} \dot{0} \dot{0} \dot{0} \dot{0} \dot{0} \dot{0} \dot{0} \dot{0} \dot{0} \dot{0} \dot{0} \dot{0} \dot{0} \dot{0} \dot{0} \dot{0} \dot{0} \dot{0}$ 害室

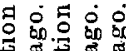
o 0 on

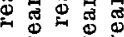
a 0 占

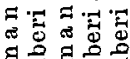

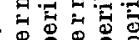
id 000

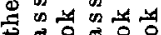

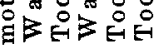

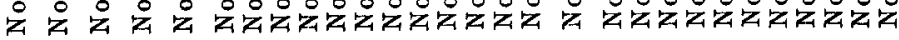




\section{TABLE IV (A).}

Distribution of Arakawa-positive, -intermediate and -negative cases according to the blood platelet count.

\begin{tabular}{|c|c|c|c|}
\hline $\begin{array}{c}\text { Blood platelet } \\
\text { count }\end{array}$ & $\begin{array}{c}\text { Strongly A rak aw a- } \\
\text { positive cases } \\
(4 \text { in all })\end{array}$ & $\begin{array}{l}\text { Cases with inter- } \\
\text { mediate A rakawa's } \\
\text { reaction (109 in all) }\end{array}$ & $\begin{array}{c}\text { Completely (or } \\
\text { almost completely) } \\
\text { Arakawa-negative } \\
\text { cases (12 in all) }\end{array}$ \\
\hline $\begin{array}{l}100,000-200,000 \\
210,000-300,000 \\
310,000-400,000 \\
410,000-500,000 \\
510,000-600,000 \\
610,000-700,000 \\
710,000-800,000 \\
810,000-900,000 \\
910,000-1000,000\end{array}$ & 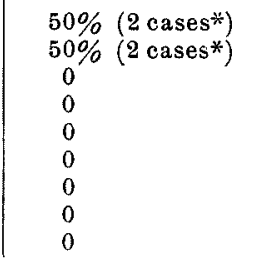 & $\begin{array}{l}0 \\
8.3 \% \text { (9 cases) } \\
37.6 \% \text { (41 cases) } \\
30.3 \% \text { ( } 33 \text { cases) } \\
17.4 \% \text { (19 cases) } \\
6.4 \% \text { ( } 7 \text { cases) } \\
0 \\
0 \\
0\end{array}$ & $\begin{array}{l}0 \\
0 \\
0 \\
0 \\
25 \% \text { ( } 3 \text { cases) } \\
41.7 \% \text { (5 cases) } \\
8.3 \% \text { (1 cases) } \\
25 \% \text { (3 cases) } \\
0 \%\end{array}$ \\
\hline
\end{tabular}

* Cf. Table VI (A), as in this table (Table IV) strongly A raka w a-positire cases are only a few in number.

\section{TABLE IV (B).}

Distribution of A rakawa-positive, -intermediate and -negative cases according to the blood platelet count.

\begin{tabular}{|c|c|c|c|}
\hline $\begin{array}{l}\text { Blood platelet } \\
\text { count }\end{array}$ & $\begin{array}{c}\text { Strongly A raka wa- } \\
\text { positive cases } \\
(4 \text { in all })\end{array}$ & $\begin{array}{l}\text { Cases with inter- } \\
\text { mediate } A \text { rak a wa's } \\
\text { reaction }(109 \text { in all })\end{array}$ & $\begin{array}{l}\text { Completely (or } \\
\text { almost completely) } \\
\text { Arak a a-negative } \\
\text { cases (12 in all) }\end{array}$ \\
\hline $\begin{array}{l}100,000-400,000 \\
410,000-700,000 \\
710,000-1000,000\end{array}$ & $\begin{array}{l}100 \% \text { (4 cases) } \\
0 \\
0\end{array}$ & $\begin{array}{l}45.9 \%(50 \text { cases }) \\
54.1 \%(59 \text { cases }) \\
0\end{array}$ & $\begin{array}{l}0 \\
66.7 \% \text { ( } 8 \text { cases) } \\
33.3 \% \text { ( } 4 \text { cases) }\end{array}$ \\
\hline
\end{tabular}

TABLE V.

Average of blcod platelet counts according to A rakawapositive, intermediate and -negative cases.

\begin{tabular}{c|c|c|c}
\hline & $\begin{array}{c}\text { Strongly Arakawa- } \\
\text { positive cases } \\
\text { (4 in all) }\end{array}$ & $\begin{array}{c}\text { Cases with inter- } \\
\text { rediate A rakawa's } \\
\text { reaction (109 in all) }\end{array}$ & $\begin{array}{c}\text { Completely (or } \\
\text { almost completely) } \\
\text { A raka a a-negative } \\
\text { cases (12 in all) }\end{array}$ \\
\hline $\begin{array}{c}\text { Blood platelet } \\
\text { count }\end{array}$ & 237,000 & 430,000 & 678,000
\end{tabular}




\section{TABLE VI (A).}

Distribution of A rakawa-positive, -intermediate and -negative cases according to the blood platelet count.

\begin{tabular}{|c|c|c|c|}
\hline $\begin{array}{l}\text { Blood platelet } \\
\text { count }\end{array}$ & $\begin{array}{c}\text { Strongly A ra k a wa- } \\
\text { positive cases } \\
(67 \text { in all })\end{array}$ & $\begin{array}{c}\text { Cases with inter- } \\
\text { mediate A rak a wa's } \\
\text { reaction (153 in all) }\end{array}$ & $\begin{array}{c}\text { Completely (or } \\
\text { almost completely) } \\
\text { Arak a wa-negative } \\
\text { cases (105 in all) }\end{array}$ \\
\hline $\begin{array}{l}100,000-200,000 \\
210,000-300,000 \\
310,000-400,000 \\
410,000-500,000 \\
510,000-600,000 \\
610,000-700,000 \\
210,000-800,000 \\
810,000-900,000 \\
910,000-1000,000\end{array}$ & 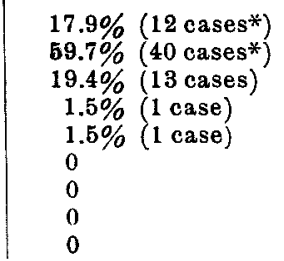 & $\begin{array}{l}0 \\
9.1 \% \text { (14 cases) } \\
35.9 \% \text { (55 cases) } \\
30.1 \% \text { (46 cases) } \\
18.9 \% \text { (29 cases) } \\
5.9 \% \text { (9 cases) } \\
0 \\
0 \\
0\end{array}$ & $\begin{array}{l}0 \\
3.8 \% \text { ( } 4 \text { cases) } \\
8.6 \% \text { (9 cases) } \\
16.2 \% \text { ( } 17 \text { cases }) \\
34.3 \% \text { (36 cases) } \\
15.2 \% \text { (16 cases) } \\
8.6 \% \text { (9 cases) } \\
10.5 \% \text { (11 cases) } \\
2.8 \% \text { ( } 3 \text { cases) }\end{array}$ \\
\hline
\end{tabular}

\section{TABLE VI (B).}

Distribution of Arakawa-positive, -intermediate and -negative cases according to the blood platelet count.

\begin{tabular}{c|c|c|c}
\hline $\begin{array}{c}\text { Blood platelet } \\
\text { count }\end{array}$ & $\begin{array}{c}\text { Strongly Arakawa- } \\
\text { positive cases } \\
\text { (67 in all) }\end{array}$ & $\begin{array}{c}\text { Cases with inter- } \\
\text { mediate Arakawa's } \\
\text { reaction (153 in all) }\end{array}$ & $\begin{array}{c}\text { Completely (or } \\
\text { almost completely) } \\
\text { Arakawa-negative } \\
\text { cases (105 in all) }\end{array}$ \\
\hline $100,000-400,000$ & $97 \%$ (65 cases) & $45.1 \%$ (69 cases) & $12.4 \%$ (13 cases) \\
$410,000-700,000$ & $\mathbf{3} \%$ (2 cases) & $54.9 \%$ (84 cases) & $65.7 \%$ (69 cases) \\
$710,000-1000,000$ & 0 & 0 & $21.9 \%$ (23 cases)
\end{tabular}

\section{TABLE VI (C).}

Average of blood platelet count according to Arakawapositive, intermediate and -negative cases.

\begin{tabular}{c|c|c|c}
\hline & $\begin{array}{c}\text { Strongly Arak a w a- } \\
\text { positive cases } \\
\text { (67 in all) }\end{array}$ & $\begin{array}{c}\text { Cases with inter- } \\
\text { mediate A r k a wa's } \\
\text { reaction (153 in all) }\end{array}$ & $\begin{array}{c}\text { Completely (or } \\
\text { almost completely) } \\
\text { Arak a wa-negative } \\
\text { cases (105 in all) }\end{array}$ \\
\hline $\begin{array}{c}\text { Blood platelet } \\
\text { count }\end{array}$ & 265,000 & 430,000 & $\mathbf{5 7 3 , 0 0 0}$
\end{tabular}

As to the average count of each group, the following will show a rough proportion (Cf. Table VIc and Figure).

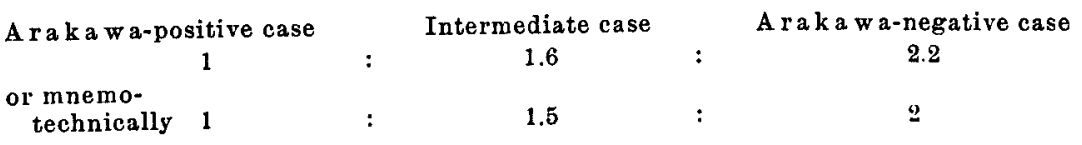


Fig. 1. Distribution of A rakawa-positive, -intermediate and -negative cases.

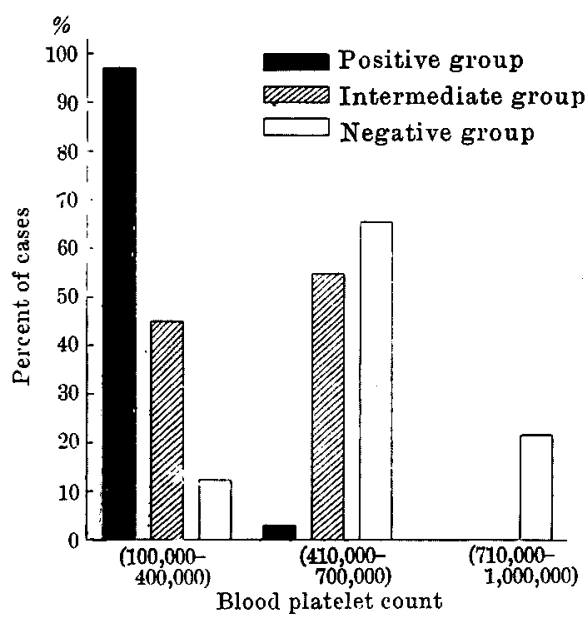

5. Change of blood platelet count according to change of Arakawa's reaction of medication of vi$\operatorname{tamin} B$ in one and the same lactants.

As was shown in the last paragraph, the blood count varies not so much according to lactants as according to Arakawa's reaction of the lactants. Now Arakawa's reaction is, as Arakawa's experiment ${ }^{9)}$ shows, made from negative to positive on administration of vitamin $B$, though the amount of this is

different according to cases. The experiment in human cases has been, and is, daily going on in our Department. Takamatsu's ${ }^{5)}$ paper verifies this. Now, almost all B-avitaminotic lactants seen in daily practice are not acute cases, of course, and a daily administration of vitamin $B$ in a not very large amount cannot easily make Araka wa-negative case A rakaw a-positive, but when mothers with A rakawa-negative milk are taking vitamin $B$, the milk is losing in its toxicity or its content in glyoxal-like substances, even if it still remains negative to Araka wa's reaction all the same. This is what was shown by Takamatsu. ${ }^{5}$ )

It was difficult to examine mothers for a long time, because as soon as their infants had recovered they stopped visiting our dispensary. But I was able to follow 17 cases with the result shown in Table VII.

Most of the 17 cases given in Table VII showed an improvement of Arakawa's reaction on a daily administration of vitamin $B$, and all the cases showed a decrease in the blood platelet count. In Cases No. 12 and No. 17 Arakawa's reaction did not improve at all, as far as the reaction during the first five minutes was concerned. Yet vitamin B must have decreased the toxicity of each milk, with the platelet count showing a decrease too. Only in Case No. 17, not vitamin

5) A. Taka matsu, Tohoku J. Exp. Med., 1934, 23, 46. 


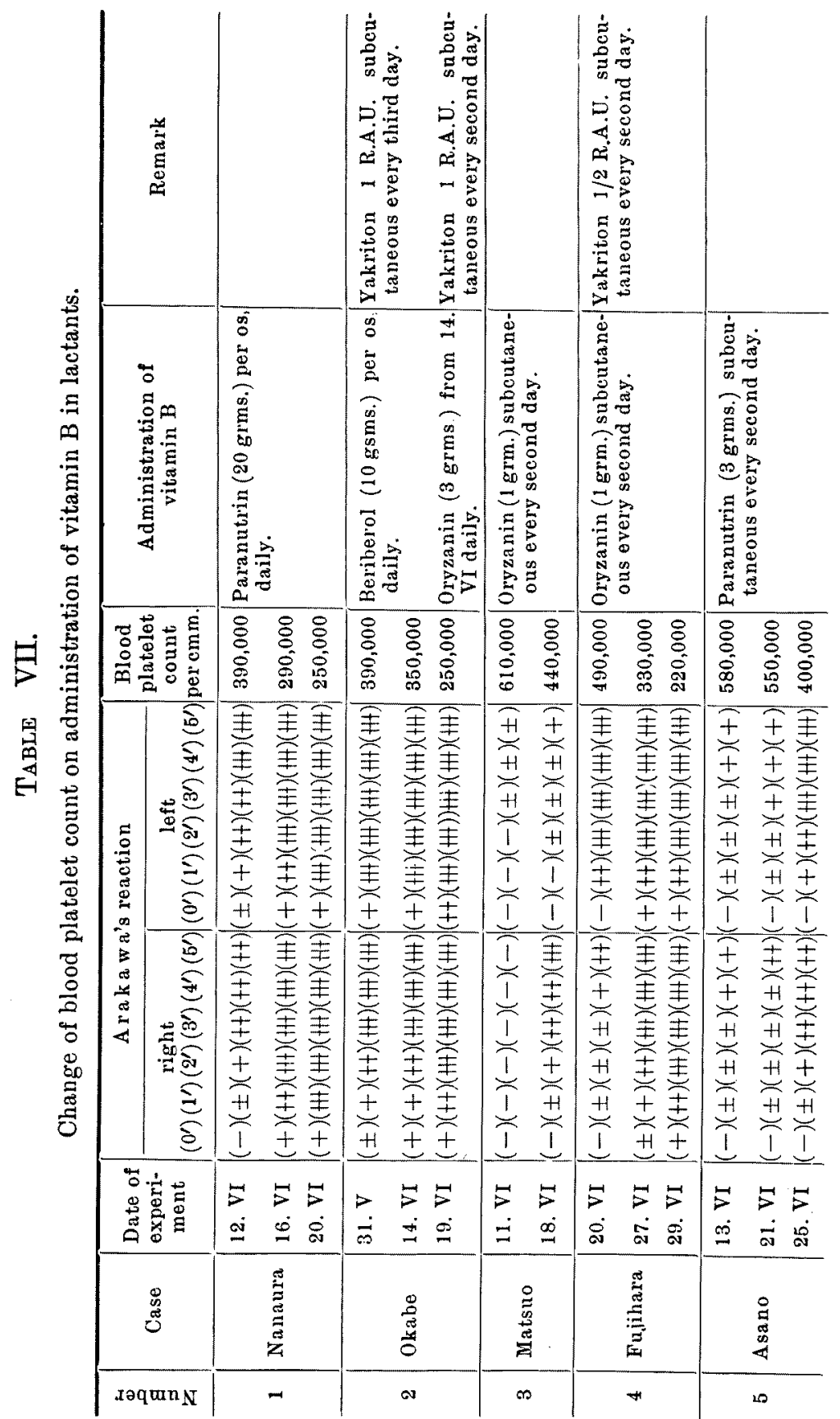




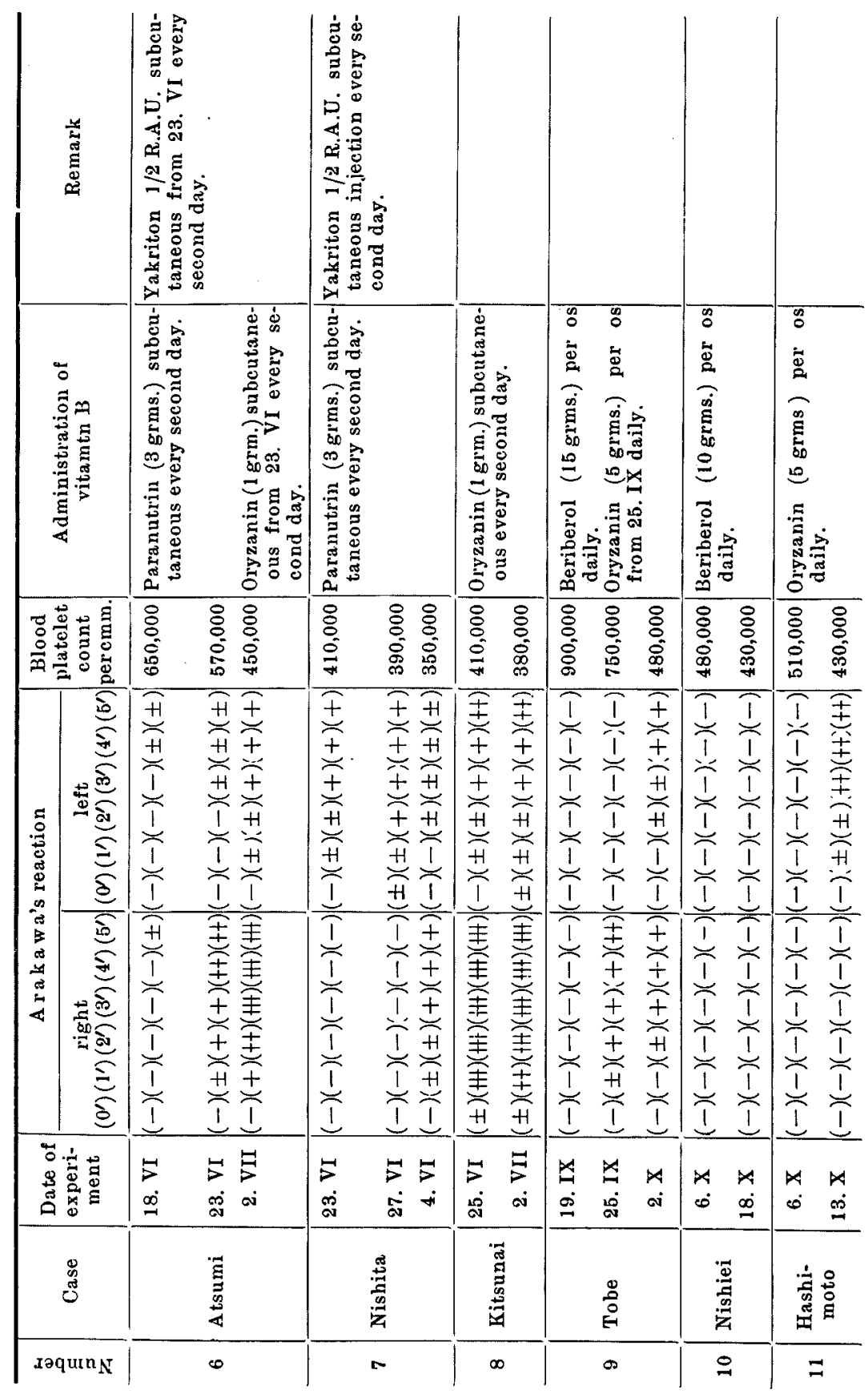




\begin{tabular}{|c|c|c|c|c|c|c|}
\hline & & & & & & \\
\hline 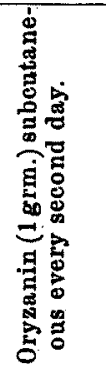 & 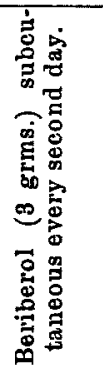 & 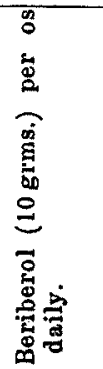 & 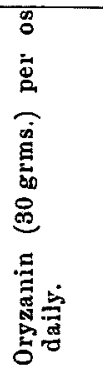 & 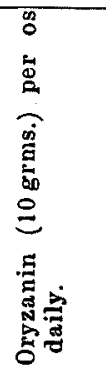 & & 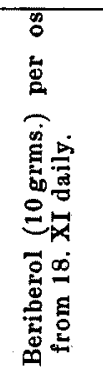 \\
\hline $\begin{array}{ll}8 & 8 \\
\delta & 0 \\
0 & 0 \\
0 & 0 \\
0\end{array}$ & 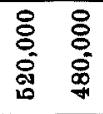 & $\begin{array}{ll}8 & 8 \\
8 & 0 \\
0 & 0 \\
8 & 0\end{array}$ & \begin{tabular}{ll}
8 & 8 \\
8 & 8 \\
8 & 8 \\
\hdashline & 8 \\
\hdashline
\end{tabular} & 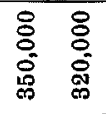 & $\begin{array}{l}8 \\
8 \\
8 \\
8 \\
10\end{array}$ & $\begin{array}{l}8 \\
8 \\
8 \\
0\end{array}$ \\
\hline 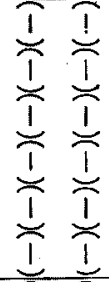 & 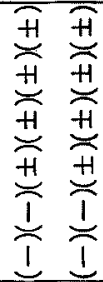 & 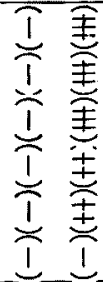 & 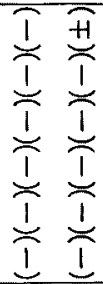 & 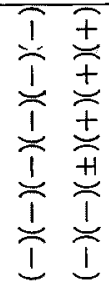 & 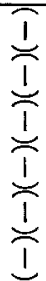 & 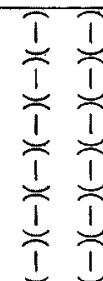 \\
\hline 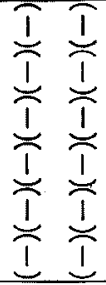 & 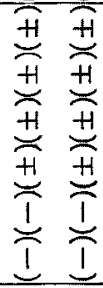 & 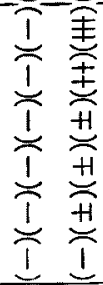 & 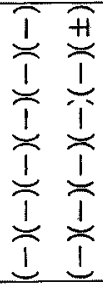 & 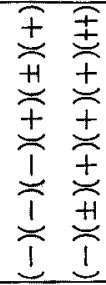 & 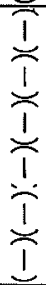 & 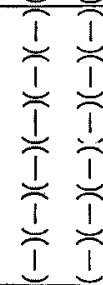 \\
\hline $\begin{array}{ll}\vec{x} & \vec{x} \\
\infty & 0 \\
\infty\end{array}$ & $\begin{array}{ll}\overrightarrow{4} & \\
\dot{0} & 0\end{array}$ & $\begin{array}{ll}\vec{\Delta} & \vec{\Delta} \\
\dot{\infty} & \infty\end{array}$ & 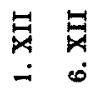 & 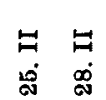 & $\frac{4}{\dot{\pi}}$ & $\begin{array}{ll}\vec{A} & \vec{X} \\
\infty & \infty\end{array}$ \\
\hline 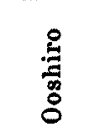 & 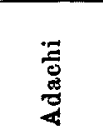 & 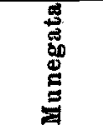 & 荧 & $\stackrel{:}{\ddot{Z}}$ & & 郎 \\
\hline $\mathbf{q}$ & $\stackrel{0}{\sim}$ & $\nexists$ & 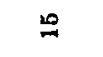 & $\cong$ & & $\Xi$ \\
\hline
\end{tabular}


B, but cod liver oil was given at first, and the blood count did not become smaller, but larger. Then cod liver oil was stopped and vitamin $B$ administered daily, the result of which was a decrease of the count. In Cases No. 2, No. 4, No. 6 and No. 7 yakriton was also used for a better mobilization of vitamin B (Cf. Takamatsu's ${ }^{6}$ paper).

This experiment on an improvement of A rak a wa's reaction with a simultaneous decrease of platelet count on an administration of vitamin $\mathrm{B}$ has much in common with the experiments of $\mathrm{Nak}$ a mura $\mathrm{u}^{7)}$ and of $\mathrm{Kooda},{ }^{8}$ who both saw a decrease of the platelet count following vitamin $B$ administration in beriberi cases.

\section{Summary.}

In the present paper I reported on the blood platelet count in mothers with milk of Arakawa's reaction of intermediate strengths between strongly positive and completely Arakawa-negative reactions. And I made a statistical investigation of all the cases reported in the 47th and the 59th Report on Peroxidase Reaction as well as in the present paper.

A rakaw $a^{97}$ of our Laboratory has shown that rabbits milk negative to Arak aw a's reaction is from a B-avitaminotic body. Human milk negative to the reaction is from a $\mathrm{B}$-avitaminotic body. A mother with Arakawa-negative milk is already in a state of avitaminosis $\mathrm{B}$, as has been shown on the basis of the blood platelet count. And, as has been shown again on the same basis, mothers with Arakawa's reaction of intermediate strengths are generally either in a state of avitaminosis B or on the brink of B-avitaminosis. This was further confirmed by the present paper.

Besides, I was able to make the platelet count smaller in cases of negative or weak A rakawa's reaction by administering vitamin $B$ to them, which fact shows again that Arakawa-negative cases are already in a state of $\mathrm{B}$-avitaminosis.

\section{Conclusions.}

On the basis of the blood platelet count it is shown-1. that Ara-

6) A. T ak a matsu, Tohoku J. Exp. Med., 1934, 23, 372.

7) N. Na k a m u ra, Nippon Naikwagakukwai Zasshi., 1925, 13, 31.

8) S. K ood a, Jika Zasshi., 1935, 607.

9) T. Arak a wa, Tohoku J. Exp. Med.. 1930, 16, 118. 
k a w a-positive cases show mostly a physiological blood platelet count, that weakly Arakawa-positive cases show generally a larger platelet count, and that A r a a wa-negative cases show the largest count, and-2. that mothers with weak or negative Arakawa's reaction show a decrease of platelet count on administration of vitamin $B$. 3. It is further confirmed that "healthy" mothers with weak or negative Arakawa's reaction are already on the brink of avitaminosis B, or in a state of avitaminosis B. 